\title{
Last gape of the Tasmanian tiger
}
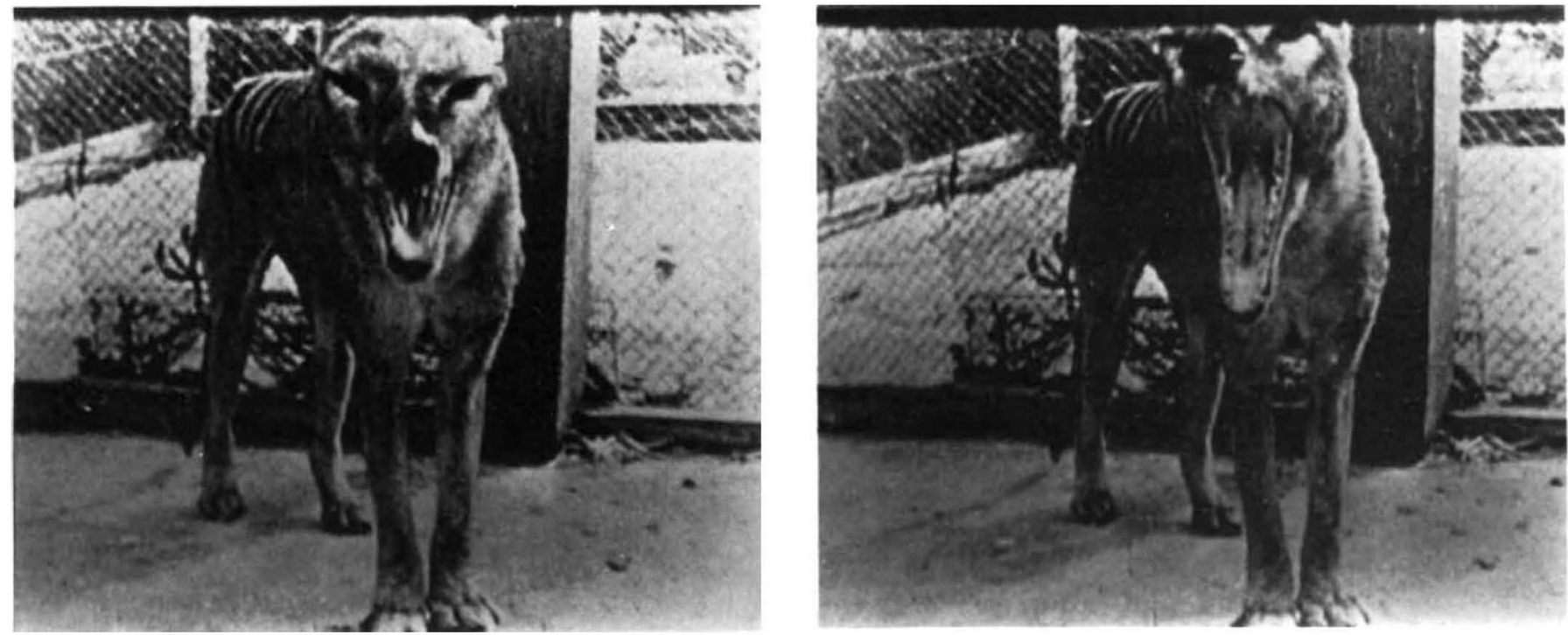

THAT most curious of marsupials, the thylacine or 'Tasmanian tiger', is commonly assumed by zoologists to be extinct. The last known specimen died in captivity in Beaumaris Zoo, Hobart on 7 September 1936 after a deadly campaign led by Tasmanian sheep-farmers over the preceding half-century. Anecdotal reports of more recent encounters notwithstanding, no solid evidence has been forthcoming since then despite several major expeditions and many forays by wildlife enthusiasts.

Thylacinus cynocephalus - literally 'pouched dog with a wolf head' - managed to combine a lupine visage with a tiger's stripes, a snake's gape, a kangaroo's

(and if there are no costs, then in the above models mutualism can of course evolve in groups of arbitrary size). Wilson suggests two kinds of cost, which he hopes to quantify in future experiments. First, since the mites' diligence in piercing every egg they can find apparently pays no dividend in enhancing reproductive success, it represents a departure from optimal foraging; this is likely to carry some cost, even in the mites' food-rich environment. Second, the habit of $P$. necrophori of leaving its beetle carrier upon discovery of a carcass incurs the substantial risk of the carcass being appropriated by some other species of animal. As Wilson observes" " A mite that abandons its carrier only to have it fly away has made a poor choice, and I do occasionally observe a few $P$. necrophori wandering forlornly around a half-built burial chamber that has been robbed by a mammal. Yet the carrier must be abandoned to pierce fly eggs. Assuming that the beetle does not force abandonment, this may represent the greatest potential cost of the mutualistic behavior".

As Wilson emphasizes ${ }^{5}$, this research programme is still in its formative stages. tail and a unique rear-opening pouch (the thylacine loped about on all fours and would otherwise have risked injury to its young from rough undergrowth). From nose to tip of tapering tail the thylacine measured up to 2 metres, in height $55 \mathrm{~cm}$ and in weight $20 \mathrm{~kg}$, thus qualifying as the largest carnivorous marsupial. Although its tawny fur and other external characteristics can be seen in pelts preserved at the British Museum (Natural History) and elsewhere, the astonishing capacity to open its jaws to an angle of over $120^{\circ}$ is best appreciated on this unique surviving photograph, the last recorded gape of the Hobart specimen circa 1935. The two frames are reproduced from an 8-mm film by courtesy of the State Library of Tasmania.

The latest in a long line of claimed sightings was made in 1982 in northwestern Tasmania by a ranger of the National Parks and Wildlife Service, according to just released press reports. The news had been kept secret to deter hunters and sightseers, but the deployment of trip cameras and sand traps over the last eighteen months yielded neither photographs nor spoor.

This is the first in a series of historic scientific photographs which will be appearing in News and Views. They are selected from Beyond Vision by Jon Darius, to be published in April by Oxford University Press.
The existing work does a lot towards quantifying the benefits and the population structure of one particular mite-beetle association, but there is a need for more information (particularly about the costs). Beyond this, it can more generally be remarked that burying beetles live in a very competitive environment, where their relatively slowly developing larvae (the eggs hatch several days after the carcass is buried, and larvae take 10 to 20 days to complete their development) must contend both with faster developing flies (where the span from egg to adult fly takes seven days or less) and with the problem of 'spoilage' of the carcass by microbial activities. The mite $P$. necrophori is just one member of a diverse phoretic community; $N$. orbicollis species in northern Michigan, for example, typically carry seven species of mites and at least one nematode species. Wilson suggests that, as most of the mites filter microorganisms, these mite-beetle associations may represent elaborately co-evolved mutualisms (with prevention of spoilage of the buried carcass being an important component), in spite of average group sizes exceeding 100 mites per beetle. He concludes that ${ }^{5}$ " it seems possible that the beetles and their phoretic associates have congealed into a multispecies mutualistic network that systematically alters the local environment in ways that cause its own perpetuation. If so, then the structure of these miniature communities more closely resembles the view of Allee et al. ${ }^{7}$ than more modern ecological theories". In its larger aspects, Wilson's experimental study will of necessity unfold slowly.

Robert M. May is Class of 1877 Professor of Zoology at Princeton University, Princeton, New Jersey 08544.

. Lewin, R. Science 221, 636; 737 (1983)

2. Harvey, P. \& Silvertown, J. New Scient. 99, 760 (1983).

3. May, R.M. (ed.) Theoretical Ecology. Second Edition Ch.S (Blackwell, Oxford, 1981).

4. May, R.M. Nature 29, 803 (1982).

5. Wilson, D.S. Am. Nat. 121, 851 (1983).

6. Williams, G.C. Adaptation and Natural Selection (Princeton University Press, 1966).

7. Allee, W.C., Emerson, A.E., Park, O., Park, T. \& Schmidt, K.P. Principles of Animal Ecology (Saunders, Philadelphia, 1949).

8. Wilson, D.S. Proc. natn. Acad. Sci. U.S. A. 72, 143 (1975)

9. Wilson, D.S. The Natural Selection of Populations and Communities (Benjamin, Menlo Park, 1980).

10. Wade, M.J. O. Rev, Biol 53, 101 (1978).

11. Uyenoyama, M. \& Feldman, M.W. Theor. Pop. Biol. 17, 380 (1980).

12. May, R.M. Nature 254, 485 (1975). 